\title{
Correction to: Anomalies in Punjabi Language WordNet: An IndoWordNet Evaluation
}

Monica Bianchini, Vincenzo Piuri, Sanjoy Das, and Rabindra Nath Shaw

\section{Correction to:}

Chapter "Anomalies in Punjabi Language WordNet:

An IndoWordNet Evaluation" in: M. Bianchini et al. (eds.), Advanced Computing and Intelligent Technologies,

Lecture Notes in Networks and Systems 218, https://doi.org/10.1007/978-981-16-2164-2_44

The original version of the book was inadvertently published with incorrect Gurmukhi (Panjabi) words in chapter "Anomalies in Punjabi Language WordNet: An IndoWordNet Evaluation". The correction chapter and the book have been updated with the change. 